J. Lake Sci.(湖泊科学), 2018, 30(1): 171-182

DOI 10. 18307/2018. 0117

(c) 2018 by Journal of Lake Sciences

\title{
淮南迪沟采煤沉陷区湖泊后生浮游动物群落结构及其影响因子
}

\author{
林 志,万阳,徐 梅, 汪晨琛, 吴奇丽, 周忠泽** \\ (安徽大学资源与环境工程学院,合肥 230601)
}

\begin{abstract}
摘 要: 2015 年 8 月- 2016 年 6 月对安徽省迪沟采煤沉陷区湖泊后生浮游动物群落结构及环境因子进行了调查, 研究了 其群落结构及与环境因子的关系. 共发现后生浮游动物 16 科 27 属 53 种, 其中轮虫 38 种, 枝角类 9 种, 桡足类 6 种, 优势 种为萼花臂尾轮虫 (Brachionus calyciflorus)、角突臂尾轮虫 (B. angularis)、蒲达臂尾轮虫 (B. budapestiensis)、针簇多肢轮虫 (Polyarthra trigla)、曲腿龟甲轮虫 (Keratella valga) 、螺形龟甲轮虫 ( K. cochlearis)、长额象鼻溞 (Bosmina longirostris) 和透明 温剑水蚤 (Thermocyclops hyalinus). 密度和生物量平均值分别为 $965.00 \pm 541.91 \mathrm{ind} . / \mathrm{L}$ 和 $3.42 \pm 2.17 \mathrm{mg} / \mathrm{L}$. 密度峰值出现 在 2015 年 2 月, 而生物量峰值出现在 10 月, 最低值均出现在 12 月. 后生浮游动物密度的空间分布呈现西低东高的趋势, 而生物量空间分布呈现西高东低的趋势. Shannon-Wiener 多样性指数、Margalef 丰富度指数和 Pielou 均匀度指数分别为 2.07 3.22、0.83 1.72 和 $0.67 \sim 0.80$. 圥余分析及 Pearson 相关性分析结果表明, 浮游植物生物量、水温、营养盐等是影响后 生浮游动物群落结构的主要因子. 综合理化指标、营养状态指数、后生浮游动物优势种及生物多样性指数结果表明, 迪沟 采煤沉陷区湖泊已处于轻度富营养状态.
\end{abstract}

关键词: 后生浮游动物; 群落结构; 环境因子; 采煤沉陷区; 生态修复; 湖泊

\section{Metazoan zooplankton community structure and environmental drivers of Digou coal min- ing subsided lakes in Huainan}

\author{
LIN Zhi, WAN Yang, XU Mei, WANG Chenchen, WU Qili \& ZHOU Zhongze ${ }^{* *}$ \\ (School of Resources and Environmental Engineering, Anhui University, Hefei 230601, P.R.China)
}

\begin{abstract}
Metazoan zooplankton and environmental factors in Digou coal mining subsided lakes in Anhui Province were investigated bimonthly from August 2015 to June 2016. Metazoan zooplankton community structure and its relationships with environmental factors were analyzed. A total of 53 species from 27 genera of metazoan zooplankton were identified which consisted of 38 species of rotifers, 9 species of cladocerans and 6 species of copepoda. According to the abundance and occurrence, Brachionus calyciflorus, B. angularis, B. budapestiensis, Polyarthra trigla, Keratella valga, K. cochlearis, Bosmina longirostris and Thermocyclops hyalinus were the dominant species. The mean density and biomass of metazoan zooplankton were $965.00 \pm 541.91$ ind./L and $3.42 \pm 2.17$ $\mathrm{mg} / \mathrm{L}$, respectively. The density was highest in February, and lowest in December 2015, with the spatial pattern of increasing from west to east. The biomass was highest in October, and lowest in December 2015, with the spatial pattern of decreasing from west to east. The Shannon-Wiener index, Margalef index and Pielou index of the metazoan zooplankton community were 2.07-3.22, 0.831.72 , and $0.67-0.80$, respectively. The results of redundancy analysis and the Pearson correlation analysis indicated that phytoplankton biomass, water temperature and nutrient were the three main environmental drivers affecting the metazoan zooplankton community structure in Digou coal mining subsided lakes. The physical-chemical parameters, trophic state index, the dominant species of metazoan zooplankton and biodiversity index indicated that the lake was under light eutrophication.
\end{abstract}

Keywords: Metazoan zooplankton; community structure; environmental factors; coal mining subsidence area; ecological restoration; lakes

* 安徽省自然科学研究重大项目 (KJ20152D04) 和安徽省国土资源科技项目(2013-K-07) 联合资助. 2017-03-08 收 稿; 2017-05-31 收修改稿. 林志(1992 ), 男,硕士; E-mail: 18856962192@163.com.

** 通信作者; E-mail: zhzz@ ahu.edu.cn. 
淮南是一座有着近百年煤炭开采史的煤炭资源大市, 矿区煤炭资源丰富, 生产规模大. 由于该区域潜水 位高, 因此煤炭开采形成了一种特殊的地表水体一一采煤沉陷水体 ${ }^{[1]}$. 采煤沉陷区水体大多是封闭性水体, 但部分区域与原有水系连通, 沉陷区生态环境类型多样,水体受煤矸石堆和周边农业生产影响. 随着开采程 度的不断加深, 塌陷状况不断加剧, 沉陷面积逐年增加, 形成了一种不可忽视的地表水体资源 ${ }^{[2]}$, 执行着水 源保护地、渔业活动区、湿地生态恢复等不同的水体功能 ${ }^{[3]}$, 对矿区社会经济和生态环境可持续发展具有重 要作用 ${ }^{[4]}$. 近年来,塌陷区水质受农业面源污染和城区生活污水排放的影响而发生改变 ${ }^{[5]}$, 水体受到不同程 度的污染, 沉陷区水体的富营养化逐渐加重 ${ }^{[4,6-8]}$.

浮游动物是湖泊生态系统食物链及生物生产力的基本环节, 将能量从低营养级转移到更高的营养 级 ${ }^{[9]}$, 且浮游动物具有个体小、生殖速率快、种群密度通常较高、容易受到理化因子影响等特点, 利用浮游动 物群落结构的综合指标可以评价水质及其变化趋势 ${ }^{[10-11]}$. Sommer 等采用 Plankton Ecology Group (PEG) Model 的模型对浮游动物季节性变化所受到的影响进行描述, 表明浮游动物群落结构的季节性演替是群落 重复构建的过程, 是营养限制、食物限制和鱼类捕食等所有外部和内部因素相互作用的过程, 季节交替造成 的环境变化和生物的长期演替迫使浮游动物产生不同程度的响应 ${ }^{[12]}$. 目前已有研究表明, 采煤沉陷区湖泊 浮游动物存在特殊的群落结构特征, 如王振红等研究发现采煤沉陷区湖泊浮游动物种类明显较少, 且优势 种也不同, 浮游生物的演替不同于一般的水库和湖泊 ${ }^{[13]}$, 邓道贵等也发现采煤塌陷水体的轮虫特征与其他 富营养化水体的轮虫种类和多样性变化趋势不同, 而浮游甲壳动物的季节演替与典型温带湖泊 PEG 的模式 相一致 ${ }^{[14-15]}$. 已有研究主要集中在水温、营养盐、浮游植物生物量等理化因素对浮游动物群落结构的影响方 面 ${ }^{[3,8]}$, 而针对采煤沉陷区湖泊这一特殊生境对浮游动物群落结构影响的研究较少. 本研究在前人的基础 上, 探讨了水系连通、大型水生植被与煤研石堆对迪沟采煤沉陷区湖泊后生浮游动物群落结构的影响.

本文研究了迪沟采煤沉陷区湖泊后生浮游动物群落结构的时空动态, 通过冗余分析 (RDA) 和相关性分 析, 探讨其群落结构与环境因子之间的关系, 确定影响其群落结构的主要因素, 以期为采煤沉陷湖泊有效治 理和可持续利用提供科学数据支撑.

\section{1 材料与方法}

\section{1 研究地点}

迪沟采煤沉陷区湖泊 ( $32^{\circ} 46^{\prime} 14^{\prime \prime} \sim 32^{\circ} 47^{\prime} 57^{\prime \prime} \mathrm{N}, 16^{\circ} 20^{\prime} 55^{\prime \prime} \sim 16^{\circ} 26^{\prime} 28^{\prime \prime} \mathrm{E}$ ) 位于安徽省颖上县迪沟镇谢桥 矿, 北靠西淝河, 南临济河, 主要由农田塌陷而成, 由西部、中部和东部 5 部分水域组成 (图 1). 迪沟采煤沉 陷区生境存在明显的 4 种类型, 西部的 H1 和 H2 水域由公路分开, 其中 H1 是封闭性的水域, H2 与济河相连 通, 整个西部区域水体深, 周边有小面积的挺水植物, 未发现沉水植物; 中部的 H3 和 H4 均与济河连通, H3 周围有煤研石堆, 堆积面积约 $13.33 \mathrm{hm}^{2}$, 其水域底部由煤矸石填充, 调查中未发现沉水植物, $\mathrm{H} 4$ 沉陷时间较 短, 整体水位较低, 由于与济河相通, 济河为该区域提供了丰富的沉水植物繁殖体, 因此该水域沉水植被发 育良好, 优势群丛有大茨藻 (Najas marina) 群丛、黑藻 (Hydrilla verticillata) 群丛等; 东部水域 H5 与西泪河连 通, 沉陷时间最久, 最深区达到 $9 \mathrm{~m}$, 周边分布有小面积的水花生 (Alternanthera philoxeroides) 群丛、酸模叶蓼 (Polygonum lapathifolium) 群丛等挺水植被.

\section{2 样点设置与采样时间}

本研究共设置 12 个采样点 (图 1). 西边小型封闭水域 H1 设置采样点 D1、D2 和 D3; 中部与济河连通的 $\mathrm{H} 2$ 水域设置 D4、D5 和 D6 采样点; 中部煤研石堆积区的 H3 水域设置 D7 和 D8 采样点; 中部沉水植物茂盛 的水域 $\mathrm{H} 4$, 设置 D9 和 D10 采样点; 与西淝河的支流连通的 H5 水域设置 D11 和 D12 采样点. 于 2015 年 8 月-2016 年 6 月每 2 个月采样 1 次,采样时间为每月的上旬.

\section{3 样品采集与处理}

轮虫的定性样品用 $25^{\#}$ 浮游生物网在表层水体呈 “ $\infty$ ” 字形捞取, 放人样品瓶中, 用 $4 \%$ 福尔马林固定. 定量样品用有机玻璃采水器分层采集混合水样 $1 \mathrm{~L}$, 用鲁哥试剂固定, 样品带回实验室沉淀浓缩定容至 30

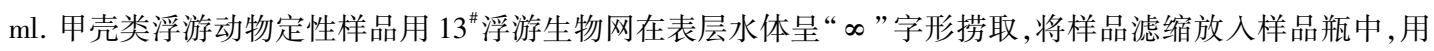
$4 \%$ 福尔马林固定. 定量样品用有机玻璃采水器分层采集混合水样 $10 \mathrm{~L}$, 滤缩至 $30 \mathrm{ml}$, 用 $4 \%$ 的福尔马林固 
定. 主要参照文献[16-19],在显微镜下对浮游动物进行分类和计数.

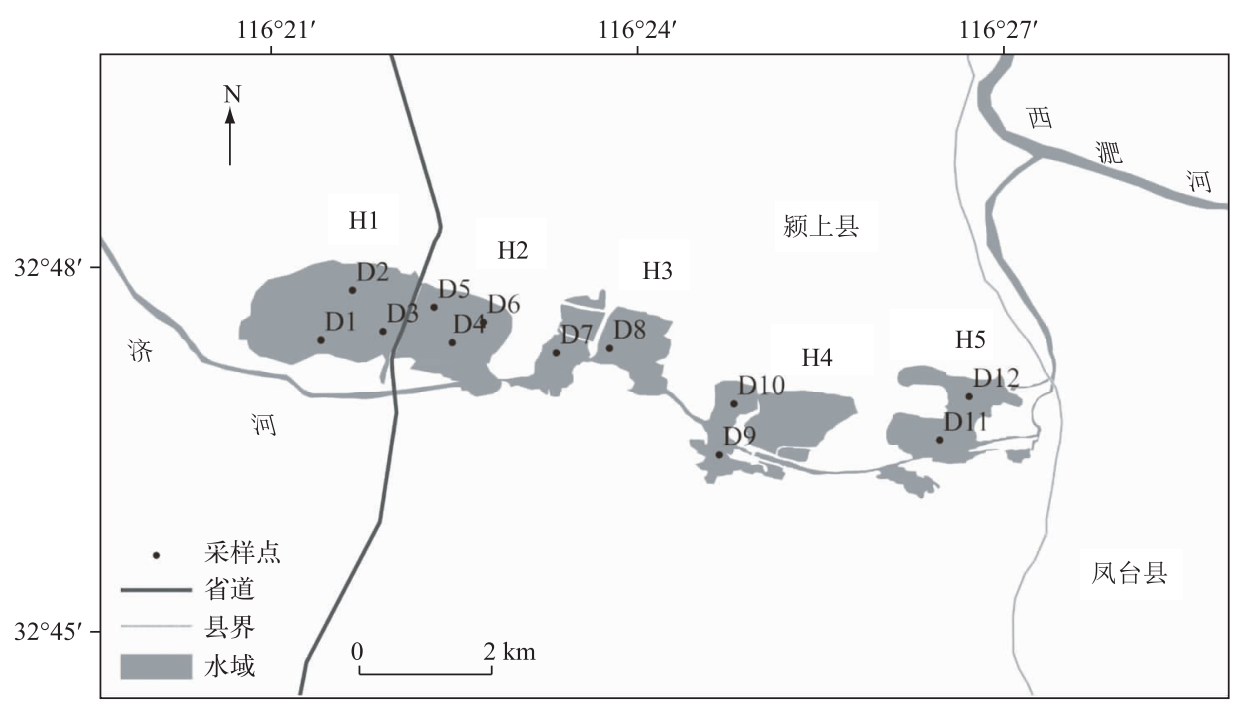

图 1 迪沟沉陷区湖泊采样点分布

Fig.1 Distribution of sampling sites in Digou coal mining subsided lakes

进行后生浮游动物样品采集的同时, 现场测定水温 ( Tem)、 $\mathrm{pH}$ 值、电导率 ( Cond)、溶解氧 ( DO)、透明度 (SD) 等理化因子, 另取适量水样带回实验室后依据《地表水环境质量标准》( GB 3838-2002) 对总氮 $(\mathrm{TN})$ 、总磷 $(\mathrm{TP})$ 、铵态氮 $\left(\mathrm{NH}_{4}^{+}-\mathrm{N}\right)$ 、硝态氮 $\left(\mathrm{NO}_{3}^{-}-\mathrm{N}\right)$ 、化学需氧量 $\left(\mathrm{COD}_{\mathrm{Cr}}\right)$ 等指标进行测定 ${ }^{[20]}$, 叶绿素 $\mathrm{a}$ (Chl.a) 浓度采用分子苂光法分析测定, 浊度 (Tur) 采用浊度仪测定.

\section{4 数据处理}

浮游动物群落结构特征采用生物多样性指数进行表征, Shannon-Wiener 多样性指数 $\left(H^{\prime}\right) 、$ Margalef 丰富 度指数 $(D)$ 和 Pielou 均匀度指数 $(J)$ 的计算公式分别为:

$$
\begin{gathered}
H^{\prime}=-\sum_{i=1}^{S}\left(n_{i} / N\right) \log _{2}\left(n_{i} / N\right) \\
D=(S-1) \log _{2} N \\
J=H^{\prime} / \log _{2} S
\end{gathered}
$$

浮游动物的优势度计算公式为:

$$
Y=\frac{n_{i}}{N} f_{i}
$$

式中, $S$ 为群落中的物种数目, $N$ 为采集样品中的所有种类总个体数, $n_{i}$ 为采集样品中第 $i$ 种个体数, $f_{i}$ 为该种 在各站点出现的频率.

水体营养状态参数的计算采用均值、标准差的方法, 选取 SD 、TN、TP 和 Chl.a 4 个指标, 用综合营养状态 指数进行评价, 计算公式为 ${ }^{[4,21]}$ :

$$
\begin{aligned}
\operatorname{TLI}\left(\sum\right) & =\sum_{j=1}^{m} w_{j} \cdot \operatorname{TLI}(j) \\
w_{j} & =r_{i j}^{2} / \sum_{j=1}^{m} r_{i j}^{2}
\end{aligned}
$$

式中, $T L I(\Sigma)$ 表示综合营养状态指数; $w_{j}$ 为第 $j$ 种参数的营养状态指数的相关权重; $r_{i j}$ 为第 $j$ 种参数与基准参数 Chl. a 的相关系数, $m$ 为评价参数的个数; $T L I(j)$ 为代表第 $j$ 种参数的营养状态指数, 分别由以下公式计算:

$$
\begin{gathered}
\operatorname{TLI}(\text { Chl.a })=10(2.5+1.086 \ln \text { Chl.a }) \\
T L I(\text { TP })=10(9.436+1.624 \ln \text { TP })
\end{gathered}
$$




$$
\begin{aligned}
& T L I(\mathrm{TN})=10(5.453+1.694 \ln \mathrm{TN}) \\
& T L I(\mathrm{SD})=10(9.463+2.661 \ln \mathrm{SD})
\end{aligned}
$$

式中, Chl. a 为叶绿素 $\mathrm{a}$ 浓度 $(\mu \mathrm{g} / \mathrm{L}), \mathrm{TP}$ 为水中总磷浓度 $(\mathrm{mg} / \mathrm{L}), \mathrm{TN}$ 为水中总氮浓度 $(\mathrm{mg} / \mathrm{L}), \mathrm{SD}$ 为湖水透 明度 $(\mathrm{m})$. 首先计算各站点每个月所有水质采样点营养盐和状态指数的均值, 然后以年均值和标准差来表 征水域总体营养状况.

采用反距离权重法, 利用 ArcGIS 10.2 软件绘制密度和生物量的空间分布图. 采用 SPSS 19.0 进行相关 性分析. 由于后生浮游动物和理化指标的原始数据变异程度较大, 因此, 原始数据通过 $\lg (x+1)$ 转换以满足 方差分析所需的正态性, 用 Canoco 4.5 软件对后生浮游动物生物量数据进行去趋势分析 (DCA), 得出第 1 轴长度小于 3(2.56), 因此选择 RDA 分析, 并通过蒙特卡罗置换检验对环境因子进行篮选, 绘制物种与环境 因子关系图.

\section{2 结果与分析}

\section{1 调查期间的水质特征}

迪沟采煤沉陷区湖泊的水温变化范围为 $6.64 \sim 29.18^{\circ} \mathrm{C}$. DO 浓度在冬季和初春较高, 在温暖季节较低, 在 2 月份最高 $(11.27 \pm 1.33 \mathrm{mg} / \mathrm{L}), 8$ 月份最低 $(5.24 \pm 1.07 \mathrm{mg} / \mathrm{L})$. TP 浓度全年变化较小, 为 $0.09 \pm 0.02 \mathrm{mg} / \mathrm{L}$. $\mathrm{TN}$ 浓度的波动较大, 6 月最高 $(4.60 \pm 2.74 \mathrm{mg} / \mathrm{L}), 10$ 月最低 $(1.80 \pm 0.12 \mathrm{mg} / \mathrm{L})$. 水体呈弱碱性, $\mathrm{pH}$ 值为 $8.37 \pm$ $0.51,2$ 月的 $\mathrm{pH}$ 值明显高于其他月份. 浮游植物的生物量 10 月最高 $(7.41 \pm 1.71 \mathrm{mg} / \mathrm{L}), 2$ 月最低 $(2.37 \pm 1.23$ $\mathrm{mg} / \mathrm{L}$ ) (表 1). TLI 均值为 $61.86 \pm 1.37$, 属于轻度富营养水体.

表 1 迪沟采煤沉陷区湖泊理化因子 (平均值土标准差) 的季节变化

\begin{tabular}{|c|c|c|c|c|c|c|}
\hline 理化参数/时间 & 8 月 & 10 月 & 12 月 & 2 月 & 4 月 & 6 月 \\
\hline 水温 $/{ }^{\circ} \mathrm{C}$ & $26.42 \pm 0.47$ & $21.10 \pm 0.54$ & $6.64 \pm 0.46$ & $12.47 \pm 0.51$ & $20.73 \pm 1.87$ & $29.18 \pm 0.48$ \\
\hline 水深/m & $4.62 \pm 2.12$ & $4.49 \pm 2.29$ & $4.88 \pm 2.08$ & $3.98 \pm 2.16$ & $4.04 \pm 2.69$ & $4.49 \pm 2.19$ \\
\hline $\mathrm{SD} / \mathrm{cm}$ & $52.9 \pm 10.5$ & $40.6 \pm 11.8$ & $71.8 \pm 13.7$ & $89.8 \pm 26.6$ & $63.2 \pm 15.8$ & $62.5 \pm 16.5$ \\
\hline Tur/NTU & $15.14 \pm 8.80$ & $14.15 \pm 10.77$ & $8.72 \pm 3.54$ & $8.94 \pm 4.19$ & $12.38 \pm 4.13$ & $11.42 \pm 5.82$ \\
\hline $\mathrm{pH}$ & $7.66 \pm 0.21$ & $8.31 \pm 0.16$ & $8.56 \pm 0.10$ & $8.92 \pm 0.14$ & $7.93 \pm 0.36$ & $8.86 \pm 0.11$ \\
\hline Cond $/(\mu \mathrm{S} / \mathrm{cm})$ & $699.42 \pm 19.93$ & $1171.25 \pm 388.35$ & $1155.50 \pm 276.18$ & $1515.00 \pm 99.43$ & $532.66 \pm 169.04$ & $561.75 \pm 46.26$ \\
\hline $\mathrm{DO} /(\mathrm{mg} / \mathrm{L})$ & $5.24 \pm 1.07$ & $9.03 \pm 1.99$ & $10.63 \pm 0.74$ & $11.27 \pm 1.33$ & $9.05 \pm 0.90$ & $10.49 \pm 1.18$ \\
\hline $\mathrm{COD}_{\mathrm{Cr}} /(\mathrm{mg} / \mathrm{L})$ & $16.66 \pm 2.41$ & $13.06 \pm 2.15$ & $12.03 \pm 4.10$ & $14.23 \pm 2.82$ & $17.65 \pm 3.84$ & $14.59 \pm 0.83$ \\
\hline $\mathrm{TN} /(\mathrm{mg} / \mathrm{L})$ & $2.86 \pm 1.35$ & $1.80 \pm 0.12$ & $2.74 \pm 0.43$ & $2.43 \pm 0.80$ & $3.22 \pm 1.14$ & $4.60 \pm 2.74$ \\
\hline $\mathrm{TP} /(\mathrm{mg} / \mathrm{L})$ & $0.11 \pm 0.03$ & $0.11 \pm 0.04$ & $0.07 \pm 0.03$ & $0.08 \pm 0.03$ & $0.09 \pm 0.03$ & $0.10 \pm 0.03$ \\
\hline $\mathrm{NH}_{4}^{+}-\mathrm{N} /(\mathrm{mg} / \mathrm{L})$ & $1.75 \pm 0.73$ & $1.13 \pm 0.28$ & $1.06 \pm 0.62$ & $0.66 \pm 0.26$ & $0.56 \pm 0.10$ & $0.51 \pm 0.11$ \\
\hline $\mathrm{NO}_{3}^{-}-\mathrm{N} /(\mathrm{mg} / \mathrm{L})$ & $0.54 \pm 0.40$ & $0.41 \pm 0.12$ & $0.92 \pm 0.25$ & $1.07 \pm 0.40$ & $0.90 \pm 0.66$ & $0.61 \pm 0.13$ \\
\hline Chl.a/( $\mu \mathrm{g} / \mathrm{L})$ & $7.60 \pm 4.36$ & $14.22 \pm 5.64$ & $6.37 \pm 3.19$ & $6.44 \pm 5.89$ & $10.99 \pm 8.10$ & $8.67 \pm 5.98$ \\
\hline 浮游植物生物量/ $(\mathrm{mg} / \mathrm{L})$ & $4.51 \pm 2.59$ & $7.41 \pm 1.71$ & $3.24 \pm 1.07$ & $2.37 \pm 1.23$ & $5.22 \pm 2.38$ & $7.23 \pm 3.10$ \\
\hline
\end{tabular}

Tab.1 Seasonal variation of physical-chemical parameters (mean \pm S.D.) in Digou coal mining subsided lakes

\section{2 后生浮游动物的种类组成}

调查期间,共记录后生浮游动物 16 科 27 属 53 种, 其中轮虫隶属 8 科 16 属 38 种,占总种数的 $71.70 \%$; 枝角类 5 科 6 属 9 种, 占总种数的 $16.98 \%$; 桡足类 3 科 5 属 6 种,占总种数的 $11.32 \% .10$ 月种类最多, 2 月和 4 月种类最少; 各个月份及总的种类组成中, 皆为轮虫所占比例最大, 枝角类和桡足类所占比例较小 (图 2).

\section{3 后生浮游动物的优势种}

根据物种优势度 $Y \geqslant 0.02$ 为优势种的原则, 优势种共有 8 种, 分别为荌花臂尾轮虫 (Brachionus calyciflorus)、角突臂尾轮虫 (B. angularis)、蒲达臂尾轮虫 (B. budapestiensis)、针簇多肢轮虫 (Polyarthra trigla)、曲腿 龟甲轮虫 (Keratella valga) 、螺形龟甲轮虫 ( $K$. cochlearis)、长额象鼻溞 (Bosmina longirostris)、透明温剑水蚤 (Thermocyclops hyalinus). 10 月曲腿龟甲轮虫的密度最大(195.73 ind./L), 其他月份较低; 蒲达臂尾轮虫密 
度在 10 月和 2 月出现两个峰值, 分别为 167.46 和 284.41 ind./L, 8 月出现最低值 ( 32.14 ind./L) ; 䓫花臂 尾轮虫密度也在 10 月和 2 月出现峰值, 分别为 106.55 和 $151.61 \mathrm{ind} . / \mathrm{L}$; 针簇多肢轮虫密度在 8 月和 2 月出现 两个峰值, 分别为 200.54 和 $269.07 \mathrm{ind}$./L, 另外 4 个月 份密度变化不大; 角突臂尾轮虫在 2 月份占据优势地 位 (334.2 ind./L); 螺形龟甲轮虫在 2 月和 4 月密度较 高, 分别为 116.58 和 $203.84 \mathrm{ind} . / \mathrm{L}$, 其他 4 个月份密度 较低. 甲壳类中, 长额象鼻溞 6 个月的密度差异明显, 10 月和 4 月较高, 分别为 124.26 和 77.94 ind. $/ \mathrm{L}, 12$ 月 与 2 月骤降; 透明温剑水蚤密度较低而且波动较小 ( $8.57 \pm 7.14$ ind./L) (图 3).

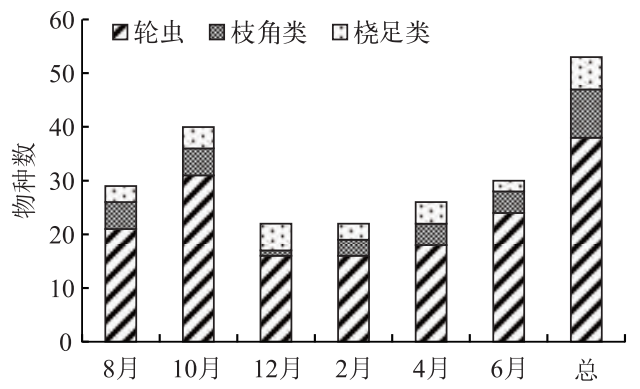

图 2 迪沟采煤沉陷区湖泊后生浮游动物种类组成

Fig.2 Species composition of metazoan zooplankton in Digou coal mining subsided lakes

\section{4 后生浮游动物的密度和生物量}

2.4.1 时间变化 后生浮游动物年平均密度为 $965.00 \pm 541.91 \mathrm{ind} . / \mathrm{L}$, 年平均生物量为 $3.42 \pm 2.17 \mathrm{mg} / \mathrm{L}$. 轮虫 年平均密度最高, 为 $794.74 \pm 500.73 \mathrm{ind} . / \mathrm{L}$, 占总密度的 $82.36 \%$, 而生物量最低, 为 $0.76 \pm 0.53 \mathrm{mg} / \mathrm{L}$; 枝角类 密度最低, 为 $54.61 \pm 50.46 \mathrm{ind} . / \mathrm{L}$, 但生物量最高, 为 $1.57 \pm 1.44 \mathrm{mg} / \mathrm{L}$; 桡足类密度和生物量分别为 $115.65 \pm$ 63.56 ind. $/ \mathrm{L}$ 和 $1.09 \pm 0.68 \mathrm{mg} / \mathrm{L}$.

(a)

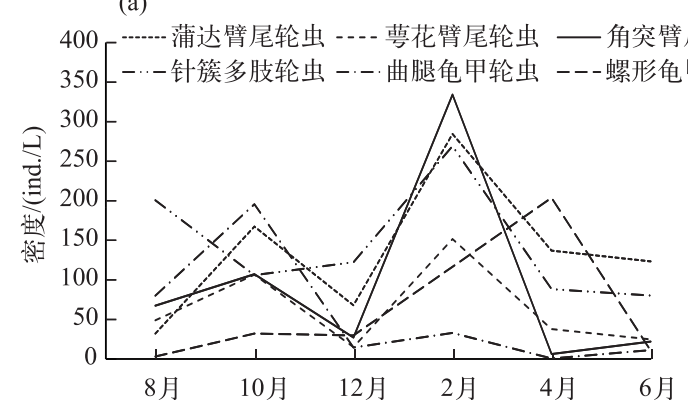

(b)

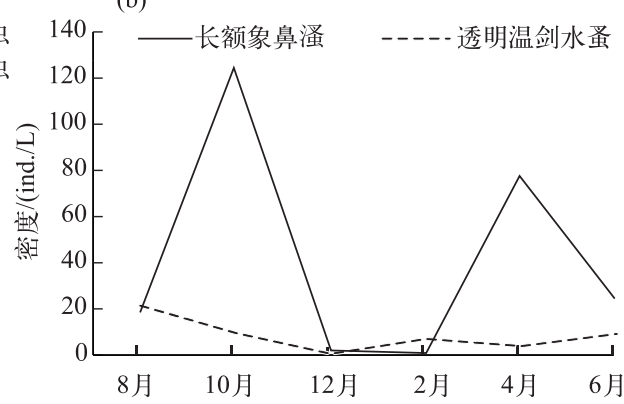

图 3 迪沟采煤沉陷区湖泊轮虫 (a) 和甲壳类 (b) 优势种密度的月变化

Fig.3 Monthly variation in density of the dominate species of rotifer (a) and crustacean zooplankton (b) in Digou coal mining subsided lakes

调查期间, 后生浮游动物密度最高值出现在 2 月, 为 $1808.12 \pm 2299.36$ ind. $/ \mathrm{L}$, 生物量最高值出现在 10 月, 为 $7.27 \pm 7.91 \mathrm{mg} / \mathrm{L}$, 这可能是由于 2 月轮虫密度明显高于其他月份, 但轮虫个体小、生物量低, 而 10 月份 枝角类密度明显高于其他月份, 且枝角类个体大、生物量高. 密度和生物量最低值均出现在 12 月份, 分别为 $329.91 \pm 202.07 \mathrm{ind} . / \mathrm{L}$ 和 $0.76 \pm 1.57 \mathrm{mg} / \mathrm{L}$ (图 4).

2.4.2 空间分布 后生浮游动物的密度和生物量具有显著的空间差异,整体来说, 密度东部比西部高, 而生物 量西部比东部高, 引起这种变化趋势的原因可能是浮游动物组成差异较大. 浮游动物密度在 D11 点位出现 最大值, 为 1682.28 ind./L, 在 D6 点位出现最低值, 为 666.72 ind./L; 浮游动物的生物量在 D1 和 D5 点位出 现两个峰值, 分别为 7.47 和 $8.73 \mathrm{mg} / \mathrm{L}$, 在 D10 点位出现最低值, 为 $1.02 \mathrm{mg} / \mathrm{L}$ (图 5).

\section{5 物种多样性}

后生浮游动物 $H^{\prime}$ 为 2.64(2.07 3.22), $D$ 为 $1.25(0.83 \sim 1.72), J$ 为 $0.74(0.67 \sim 0.80) . H^{\prime}$ 和 $D$ 的变化趋 势基本保持一致, 均在 10 月达到最高值 (分别为 3.22 和 1.72), 在 12 月达到最低值 (分别为 2.07 和 0.83 ), 而 $J$ 在调查期间变化不大 (图 6).

调查期间, $H^{\prime}$ 和 $J$ 在 H3 和 H4 区域略高于其他区域, $D$ 在 H1 和 H4 区域略高于其他区域(图 7). 

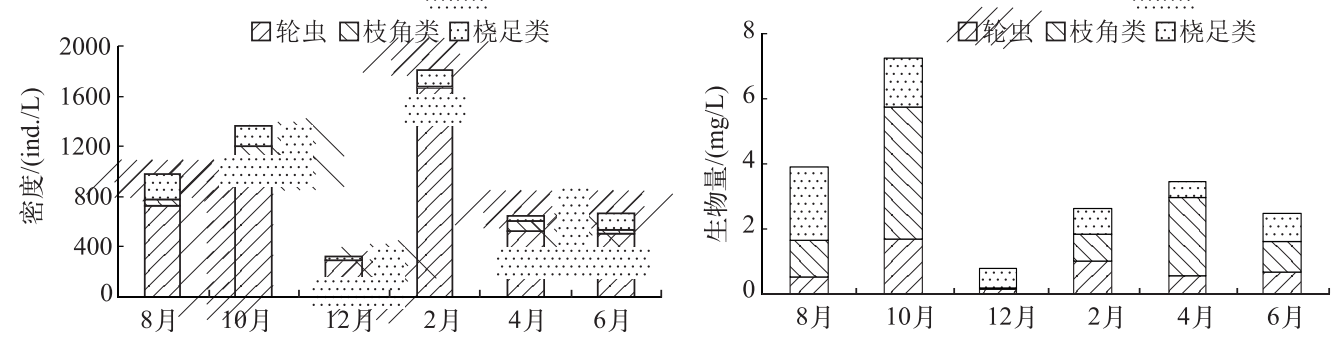

图 4 迪沟采煤沉陷区湖泊后生浮游动物密度和生物量的月变化

Fig.4 Monthly variation in density and biomass of metazoan zooplankton in Digou coal mining subsided lakes
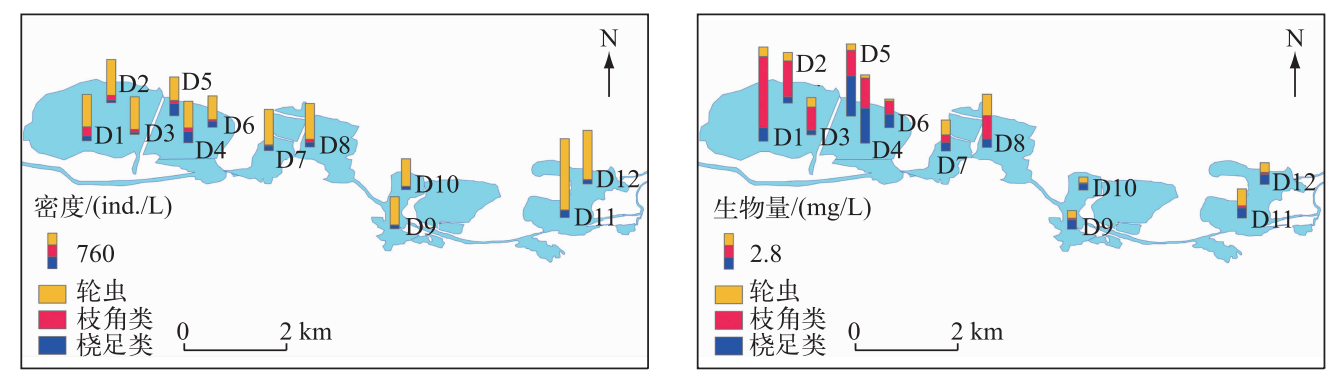

图 5 迪沟采煤沉陷区湖泊后生浮游动物密度和生物量的空间变化

Fig.5 Spatial variation in density and biomass of metazoan zooplankton in Digou coal mining subsided lakes

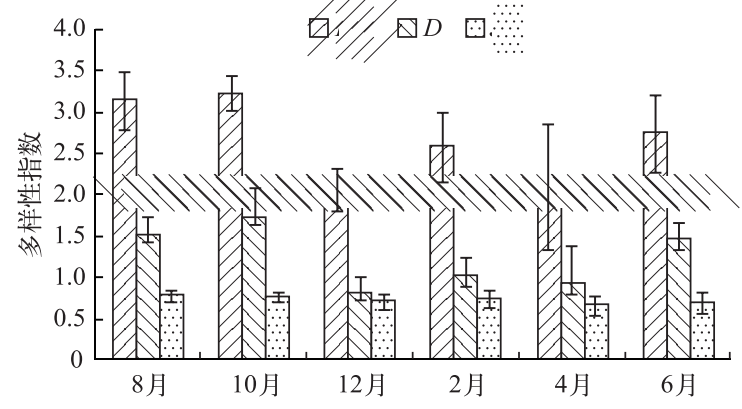

图 6 迪沟采煤沉陷区湖泊后生浮游动物群落结构多样性指数的月变化

Fig.6 Monthly variation in diversity indexes of metazoan zooplankton in Digou coal mining subsided lakes

\section{6 群落结构与环境因子的关系}

2.6.1 相关性分析 对后生浮游动物的密度和生物量与环境因子之间进行 Pearson 相关性分析, 结果表明, 轮虫密度与电导率呈显著正相关 $(P<0.05)$, 轮虫生物量与 Chl. a 浓度呈极显著正相关 $(P<0.01)$, 与 TP 浓度 呈显著正相关 $(P<0.05)$; 桡足类密度与 $\mathrm{TN}$ 浓度和水温呈显著正相关 $(P<0.05)$, 与 $\mathrm{DO}$ 浓度和 $\mathrm{SD}$ 呈显著负 相关 $(P<0.05)$, 桡足类生物量与 $\mathrm{NO}_{3}^{-}-\mathrm{N}$ 和 DO 浓度呈显著负相关 $(P<0.05)$ ( 表 2$)$.

2.6.2 攵余分析 选取 8 个全年优势种的生物量与环境因子进行进行 RDA 分析. 通过 RDA 前选和蒙特卡罗 置换检验确定水温、SD、浊度、DO 浓度、电导率、 $\mathrm{pH}$ 、浮游植物生物量、 $\mathrm{COD}_{\mathrm{Cr}}$ 浓度、TP 浓度、Chl. a 浓度共 10 个环境因子. 由表 3 和图 8 可知, 浮游植物生物量、水温、SD、浊度、DO 浓度等与后生浮游动物群落结构密切 相关.

曲腿龟甲轮虫生物量与浮游植物生物量呈正相关, 长额象鼻溞生物量与 Chl. a 浓度呈正相关, 颌花臂尾 轮虫和透明温剑水蚤生物量与 DO 浓度呈负相关, 角突臂尾轮虫、针簇多肢轮虫和蒲达臂尾轮虫生物量主要 


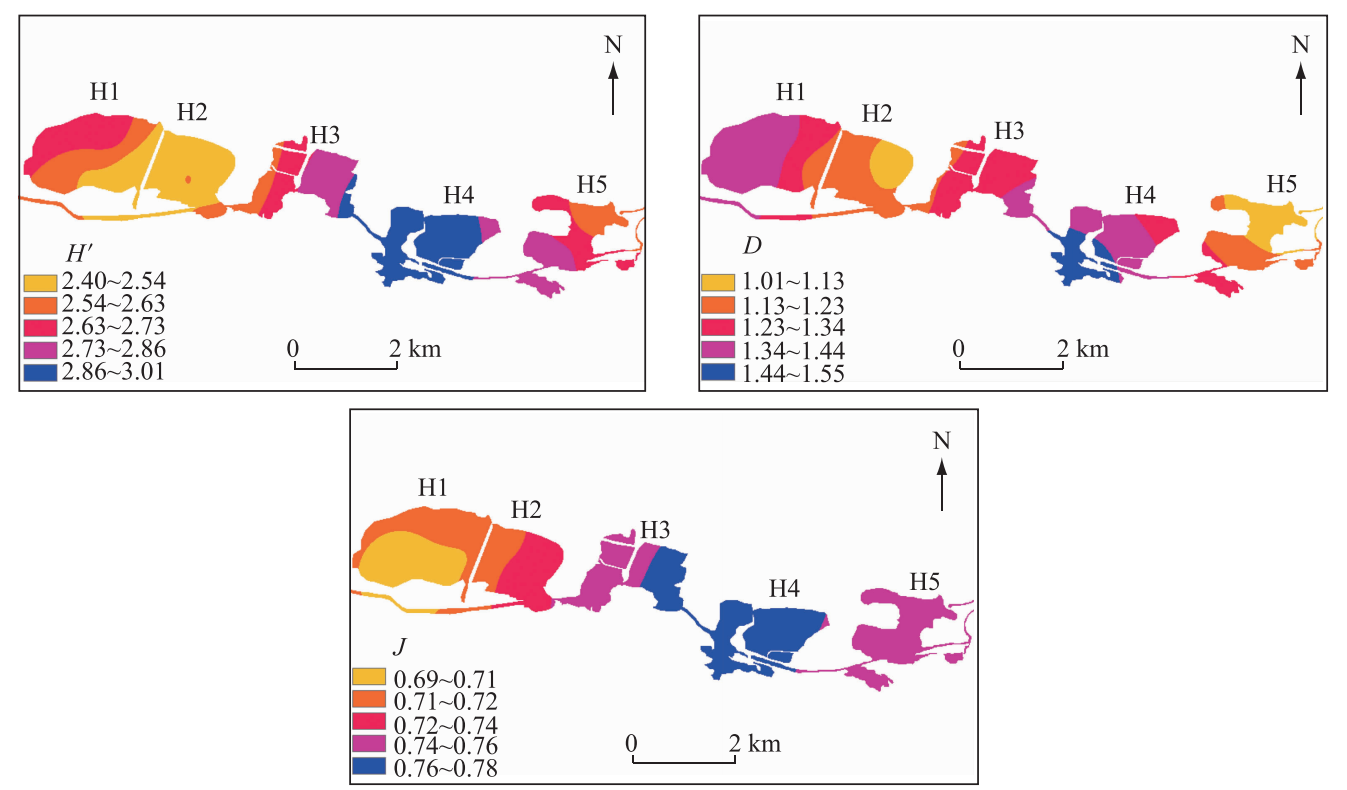

图 7 迪沟采煤沉陷区湖泊后生浮游动物多样性指数的空间分布

Fig.7 Spatial variation in diversity indexes of metazoan zooplankton in Digou coal mining subsided lakes

受电导率影响. 总体来看, 影响湖泊中后生浮游动物群落结构的主要环境因子为浮游植物生物量、电导率、 DO 浓度等.

表 2 后生浮游动物密度和生物量与理化因子的 Pearson 相关性分析

Tab.2 Pearson correlations among density, biomass and physical-chemical parameters in Digou coal mining subsided lakes

\begin{tabular}{|c|c|c|c|c|c|c|}
\hline 相关性 & 轮虫密度 & 轮虫生物量 & 枝角类密度 & 枝角类生物量 & 桡足类密度 & 桡足类生物量 \\
\hline 水温 & -0.054 & 0.117 & 0.172 & 0.130 & $0.282 *$ & 0.214 \\
\hline SD & -0.005 & -0.221 & -0.131 & -0.018 & $-0.239^{*}$ & -0.222 \\
\hline Tur & 0.060 & 0.130 & -0.157 & -0.197 & 0.093 & 0.117 \\
\hline $\mathrm{pH}$ & 0.107 & 0.011 & -0.010 & -0.111 & -0.080 & -0.164 \\
\hline Cond & $0.242^{*}$ & 0.227 & -0.135 & -0.186 & -0.014 & -0.052 \\
\hline DO & 0.063 & 0.003 & 0.091 & 0.088 & $-0.235^{*}$ & -0.240 * \\
\hline $\mathrm{COD}_{\mathrm{Cr}}$ & -0.010 & -0.066 & -0.092 & 0.078 & 0.010 & 0.103 \\
\hline $\mathrm{TN}$ & -0.029 & -0.003 & -0.108 & -0.048 & $0.288^{*}$ & 0.111 \\
\hline TP & 0.086 & $0.297^{*}$ & -0.044 & -0.012 & -0.028 & -0.150 \\
\hline $\mathrm{NH}_{4}^{+}-\mathrm{N}$ & 0.066 & 0.080 & 0.022 & -0.059 & 0.125 & 0.154 \\
\hline $\mathrm{NO}_{3}^{-}-\mathrm{N}$ & 0.142 & 0.169 & -0.229 & -0.005 & -0.194 & -0.299 * \\
\hline Chl.a & 0.101 & $0.313^{\text {*** }}$ & -0.006 & 0.016 & -0.071 & -0.144 \\
\hline
\end{tabular}

**表示在 0.01 水平 $($ 双侧 $)$ 上显著相关; * 表示在 0.05 水平 $($ 双侧 $)$ 上显著相关.

\section{3 讨论}

\section{1 水质总体评价}

采煤沉陷区多为农田塌陷而成,周围由农田环绕,化肥、农药、除草剂等的使用,使大量的氮、磷随地表 径流流人水体, 造成水体中氮、磷等营养元素的负荷明显加大. $\mathrm{COD}_{\mathrm{Cr}}$ 浓度全年都很高, 这是由于济河引人污 
表 3 迪沟采煤沉陷区湖泊后生浮游动物 生物量与环境因子的圥余分析

Tab.3 Redundancy analysis between biomass of metazoan zooplankton and environmental factors in Digou coal mining subsided lakes

\begin{tabular}{cccccc}
\hline \multirow{2}{*}{ 排序轴 } & \multirow{2}{*}{ 特征值 } & $\begin{array}{c}\text { 件种一环境 } \\
\text { 相关系数 }\end{array}$ & & \multicolumn{2}{c}{ 累计变异百分比 } \\
\cline { 5 - 6 } & & & 物种 & 物种一环境 \\
\hline 1 & 0.380 & 0.688 & 38.0 & 86.7 \\
2 & 0.340 & 0.528 & 41.4 & 94.4 \\
3 & 0.230 & 0.641 & 43.7 & 99.6 \\
4 & 0.001 & 0.504 & 43.8 & 99.8 \\
\hline
\end{tabular}

染物特别是有机物和铵态氮浓度较高的河水, 说 明其是以有机污染为主要特征的生态系统 ${ }^{[3]}$. 根 据湖泊富营养化分级标准 ${ }^{[22]}$, 迪沟采煤沉陷区湖 泊 $\mathrm{TN}$ 浓度全年均值在 $1.0 \mathrm{mg} / \mathrm{L}$ 以上, $\mathrm{SD}$ 为 63.46 $(23 \sim 135) \mathrm{cm}$, 说明其水体呈现轻度富营养状态. $T L I$ 指数为 $61.86 \pm 1.37$, 全年均在 60 以上, 表明水 体处于轻度富营养状态. 此外, 陈光荣等 ${ }^{[11]}$ 研究 发现, 浮游动物的分布情况与水体水质特征关系 密切, 清洁型水体中浮游动物的种类多、丰度小, 而富营养化的水体中一般是耐污种类形成优势 种群, 如臂尾轮虫、长三肢轮虫 (Filinia longiseta)、针簇多肢轮虫等, 此外轮虫中的前节 晶囊轮虫 (Asplanchna priodonta)、䔅花臂尾轮虫、壶状臂尾轮虫 (B. urceus) 等均被公认为是 $\alpha$-中污带至 $\beta$-中 污带的指示生物, 可作为富营养化水体的指示生物 ${ }^{[23-24]}$. 迪沟采煤沉陷区湖泊全年优势种有䓵花臂尾轮虫、 角突臂尾轮虫、蒲达臂尾轮虫、针簇多肢轮虫、曲腿龟甲轮虫、螺形龟甲轮虫、长额象鼻溞等, 均为富营养水 体指示种, 表明水体处于轻度富营养状态, 水质处于中污染状态. 生物多样性指数通过浮游动物的种类、数 量等能客观反映水域环境对生物产生的综合累积效应 ${ }^{[25]}$. 参考通用标准对水质进行初步评价, $H^{\prime}$ 为 2.64 (2.07 3.22), 表明水体处于 $\beta$-中污; $D$ 为 $1.25(0.83 \sim 1.72)$, 表明水体处于 $\alpha$-中污; $J$ 为 $0.74(0.67 \sim 0.80)$, 表明水体处于轻污染.

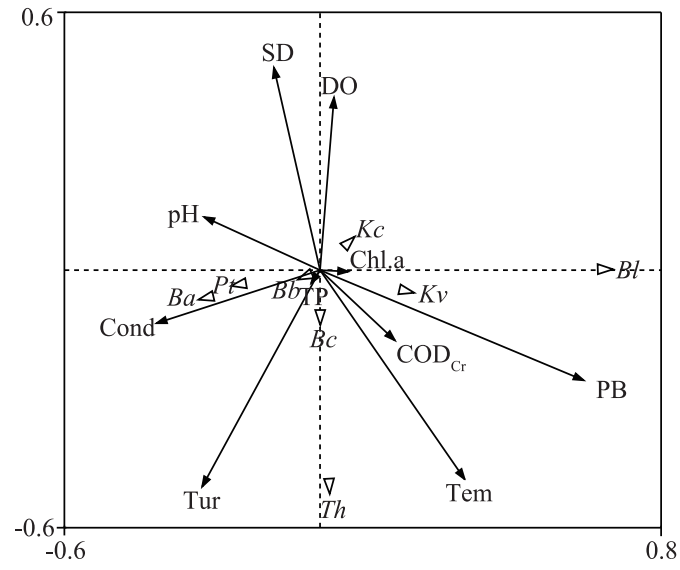

图 8 迪沟采煤沉陷区后生浮游动物优势种生物量与理化因子的圥余分析

$(P t:$ 针簇多肢轮虫; $K c$ : 螺形龟甲轮虫; $K v$ : 曲腿龟甲轮虫; $B a$ : 角突臂尾轮虫;

$B b$ : 蒲达臂尾轮虫; $B c$ : 萼花臂尾轮虫; $B l$ : 长额象鼻溞; $T h$ : 透明温剑水蚤; $\mathrm{PB}$ : 浮游植物生物量)

Fig.8 Redundancy analysis between biomass of the dominant species of metazoan zooplankton and environmental factors in Digou coal mining subsided lakes

综合理化指标、TLI 指数、优势种特征及生物多样性指数, 表明迪沟采煤沉陷区湖泊水体已处于轻度富 营养状态,水质处于中污染状态.

\section{2 环境因子对后生浮游动物群落结构的影响}

3.2.1 理化因子的影响 Pearson 相关性分析及 RDA 分析结果表明, 影响后生浮游动物群落结构的主要理化 因子为水温、电导率、 $\mathrm{SD} 、 \mathrm{NO}_{3}^{-}-\mathrm{N}$ 浓度等. 这与许多研究结果一致 ${ }^{[26-27]}$.

水温对后生浮游动物的季节演替具有重要作用 ${ }^{[28-29]}$, 本研究区域水温的季节特征明显, 冬季水温较低, 不利于后生浮游动物生长繁殖, 其密度和生物量较低; 随着水温的升高, 冬卵持续孵化, 后生浮游动物密度 
和生物量在春季达到第 1 个峰值, 轮虫密度明显增加; 夏季水温过高, 超过象鼻溞、中剑水蚤等的最适温度, 后生浮游动物密度和生物量有所降低; 10 月份水温 $(21.10 \pm 0.54)$ 降低, 枝角类如长额象鼻泽等密度显著增 加, 后生浮游动物密度和生物量达到第 2 个峰值.

氮、磷等营养盐主要通过影响作为后生浮游动物主要食物的浮游植物的生物量来对后生浮游动物的群 落结构产生影响 ${ }^{[00-31]}$, 本研究中曲腿龟甲轮虫生物量与浮游植物生物量呈正相关, 长额象鼻溞生物量与 Chl.a 浓度呈正相关, 此外, 后生浮游动物生物量与浮游植物生物量的月变化趋势基本相似, 但在 6 月, 浮游 植物的生物量较高, 后生浮游动物的生物量却较低, 这可能是夏季不能被浮游动物食用的浮游植物如蓝藻 所占的比例很高引起的.

3.2.2 鱼类捕食压力的影响 迪沟采煤沉陷区湖泊后生浮游动物群落结构的特点为小型浮游动物的种类数、 丰度所占比例均较高, 在西部 H1 和 H2 两个区域甲壳类浮游动物生物量所占比例较高, 而 H3、H4、H5 区域 轮虫生物量所占比例更高, 小型化趋势明显. 群落结构的变化是导致多样性指数、丰富度指数以及均匀度指 数变化的主要原因 ${ }^{[21]}$. 很多研究证明, 食浮游动物鱼类的捕食可以使浮游动物从大型个体向小型个体转 换, 而且营养丰富的湖泊通常具有较高捕食压力 ${ }^{[32-33]}$. 鱼类对浮游动物的捕食具有明显的选择性, 同等条件 下, 优先选择较大个体. 滤食性鱼类对浮游动物的选择性摄食, 是通过鳃耙的疏密度和浮游动物的逃逸能力 来实现的, 大型的浮游动物, 如掻类, 通常逃逸能力较差, 对鲢鳙的放养更敏感 ${ }^{[34]}$. 迪沟采煤沉陷区小型湖 泊长期养殖鲢鱼和鳙鱼, 年渔获量约 $1000 \mathrm{t}$. 后生浮游动物群落结构呈现小型化可能主要是由鲢鱼、鳙鱼滤 食导致的. 杨亮杰等 ${ }^{[25]}$ 研究发现, 个体较大的枝角类与轮虫具有竞争关系, 枝角类种类和丰度较低, 也是导 致轮虫类占绝对优势的主要原因之一. 迪沟采煤沉陷区湖泊后生浮游动物枝角类唯一优势种为小型污染种 长额象鼻溞, 对轮虫的捕食压力较小.

3.2.3 煤矸石的影响 煤研石的大量堆存给矿区的生态环境带来种种负面影响, 如占用土地、污染环境等, 且 煤研石作为一种充填材料广泛应用于铁 (公) 路、水利等, 吴代赦等以淮南潘谢矿区为例研究了煤研石的淋 溶行为对环境的影响,结果表明潘谢矿区煤研石的露天堆放、用作填充材料回填沉陷区、修筑路基等对地表 水、地下水及土壤不会造成显著的影响 ${ }^{[35]}$. 淮南矿区煤炭露天堆放, 经雨水淋溶, 其淋溶水含有一些有毒重 金属元素, 如 $\mathrm{Cd} 、 \mathrm{~Pb} 、 \mathrm{Hg} 、 \mathrm{Cr} 、 \mathrm{As}$ 等, 煤矸石淋溶液呈弱碱性, 这对水体也会产生一定程度的影响. 本文研究区 域 H1 和 H2 中间有用煤研石充填的省道 244, H3 区域附近堆有约 $13.33 \mathrm{hm}^{2}$ 的煤矸石堆, 而 H4 和 H5 区域 则距煤研石较远, 水质调查结果显示 $\mathrm{H} 1 、 \mathrm{H} 2$ 及 $\mathrm{H} 3$ 区域的 $\mathrm{pH}$ 值略高于其他区域, 水质特征无明显的空间差 异, 煤研石对水质的影响不显著. 后生浮游动物群的空间分布显示, H1、H2 及 $\mathrm{H} 3$ 区域的枝角类密度和生物 量明显高于其他区域, $H^{\prime}$ 和 $J$ 值低于其他区域, 这可能与煤䂥石堆有关. 综上所述, 煤矸石对迪沟采煤沉陷 湖泊水体影响较小, 有关煤矸石对后生浮游动物的影响有待进一步研究.

3.2.4 水系连通的影响 水系连通是指河道干支流、湖泊及其他湿地等水系的连通情况, 反映水流的连续性 和水系的连通情况. 水系连通性影响水功能区水质状况, 水系连通性越好, 水流的自净能力和纳污能力越 强, 同时河湖连通对于保持生物量和生物多样性也具有重要影响, 连通水体的生境异质性会明显提高, 从而 维持较高的物种多样性 ${ }^{[36-37]}$. 后生浮游动物大都游动能力差而营悬浮生活, 因此水系连通对浮游生物的生 长和分布有着重要的作用 ${ }^{[38-39]}$.

淮南市由于大规模的煤炭开采, 土地发生了大面积的沉陷, 大多形成封闭型的小型湖泊,如大通南大 塘、高塘湖等 ${ }^{[23,40]}$. 本研究区域迪沟采煤沉陷区湖泊与济河连通, 最终汇人西淝河, 水系连通较好的水域为 $\mathrm{H} 3$ 和 H4,3 种群落结构多样性指数均高于其他水域, 且具有明显的一致性. 这可能是因为水系连通不仅改 善了水质, 而且通过河流水体中带来的水生植物的繁殖体, 改变了该水域水生植被, 为甲壳类如剑水蚤属、 象鼻溞属等提供了适宜的生境. 与淮南大通南大塘、高塘湖等封闭型采煤沉陷区小型湖泊相比, 迪沟采煤沉 陷区湖泊 TN、TP 浓度明显较低, Chl. a 浓度略高; 后生浮游动物的种类数较少, 但均为轮虫种类数最多, 枝角 类次之, 桡足类最少; 后生浮游动物的密度和生物量均较高; 优势种均以臂尾轮属、龟甲轮属、多肢轮属、象 鼻溞属、剑水蚤等中污性物种为主. 综上, 水系连通对迪沟采煤沉陷区湖泊的水质有一定的提高作用,使后 生浮游动物的密度、生物量提高, 但研究区域与济河连通, 流速较低, 对后生浮游动物的群落结构影响不 明显. 
3.2.5 大型水生植物的影响 浮游动物群落分布很大程度上取决于水体的微环境特征, 而大型水生植物可为 浮游动物提供微环境 (如空间、食物资源等 $)^{[41]}$. 大型水生植物创建的微环境结构是决定浮游动物群落的多 样性和丰富度方面的一个重要因素. 水草对浮游动物群落结构的影响表现在一方面沉水植物可以为浮游动 物提供掩蔽所和繁殖场所, 减弱鱼类的捕食压力 ${ }^{[42-43]}$; 另一方面, 水草通过营养盐和其他生存资源的竞争, 控制浮游植物的生长, 间接地对后生浮游动物群落产生影响. 胡春英等 ${ }^{[44]}$ 对有草区和无草区不同湖泊的浮 游动物数量级多样性进行研究, 结果表明浮游动物的种类均随着水草生物量的下降而减少, 密度均随着水 草生物量的降低而升高, 多样性指数也随水草生物量的升高而升高. 陈光荣等 ${ }^{[11]}$ 对惠州西湖浮游动物群落 的研究也表明浮游动物的种类随着水草的覆盖度增加而增多,多样性也增加.

迪沟采煤沉陷区湖泊区域 H4 水草茂盛, 以大茨藻、黑藻、淔草等沉水植物为主, 区域 H3 水草较少, 主要 为水花生, 分布在桥头、岸边, 其他区域水草较少或几乎没有. $\mathrm{H} 4$ 和 $\mathrm{H} 3$ 区域 $H^{\prime} 、 D$ 和 $J$ 都高于其他区域. 这 是由于该区域沉水植物生物量较高, 已有研究表明水生植物生物量增加会使浮游动物多样性指数增加 ${ }^{[45]}$, 虽然研究区仍然以蓦花臂尾轮虫、曲腿龟甲轮虫和壸状臂尾轮虫等耐污的轮虫为主, 但是种类已趋于丰富, 说明该区域水体正逐渐好转.

\section{4 参考文献}

[ 1 ] Liu JS, Yan JP, Xu LJ et al. Environment in different subsidence pools of Huainan coal-mining area: Investigation and evaluation. Environmental Science \& Technology, 2009, 32(9): 140-143. [刘劲松, 严家平, 徐良䩀等. 淮南矿区不同 塌陷年龄积水区环境效应分析. 环境科学与技术, 2009, 32(9): 140-143.]

[ 2 ] Wang ZH, Gui HR, Luo ZX. On the aquatic environment of water logged area caused by mining coal collapsein in Huainan. Resources Survey \& Environment, 2004, 25(4) : 269-275. [王振红, 桂和荣, 罗专溪. 淮南矿区采煤塌陷积水区 水生态环境研究. 资源调查与环境, 2004, 25(4) : 269-275.]

[ 3 ] Wang XM, Yi QT, Xu X et al. Rotifer communities in the small lakes around Huainan coal mine subsidence areas. J Lake $S c i, 2015,27$ (4) : 657-666. DOI: 10.18307/2015.0414. [王晓萌, 易齐涛, 徐金等. 淮南采煤沉陷区内小型塌陷湖 泊轮虫群落结构特征. 湖泊科学, 2015, 27(4) : 657-666.]

[ 4 ] Wang TT, Yi QT, Hu YB et al. Eutrophication and nutrient enrichment bioassays in the waters of the Huainan and Huaibei coal mining subsidence areas, Anhui Province. J Lake Sci, 2013, 25 (6) : 916-926. DOI: 10.18307/2013.0616. [王婷 婷, 易齐涛, 胡友彪等. 两淮采煤沉陷区水域水体富营养化及氮、磷限制模拟实验. 湖泊科学, 2013, 25(6): 916-926.]

[ 5 ] Zhang B. Research of water environment and pollution characteristics of Linhuan coal-mine subsided area in Huaibei [ Dissertation]. Huainan: AnHui University of Science and Technology, 2012. [张冰. 淮北临涣采煤塌陷区水环境特征及 污染性状研究 [学位论文]. 淮南: 安徽理工大学, 2012.]

[ 6 ] Chen XQ, Gao LM, Zhuo LL. Temporal and spatial distribution of nitrogen and phosphorus of Xieqiao coal mining subsided water area. Environment Chemistry, 2013, 32(3): 446-450. [陈晓晴, 高良敏, 卓利玲. 谢桥采煤塌陷水域氮、磷时 空分布特征. 环境化学, 2013, 32(3): 446-450.]

[ 7 ] Zhang B, Yan JP, Fan TY et al. Evaluation and analysis of water eutrophication in coalmine subsidence area. Coal Technology, 2012, 31(1) : 159-161. [张冰, 严家平, 范廷玉等. 采煤塌陷水域富营养化评价与分析. 煤炭技术, 2012, 31 ( 1$): 159-161$.]

[ 8 ] Zhou XY. Zooplankton community structure and water-quality evaluation in coal subsidence pool. Journal of Hydroecology, 2010, 3(4) : 60-64. [ 周晓燕. 采煤塌陷塘浮游动物群落结构和水质评价研究. 水生态学杂志, 2010, 3(4): 60-64. ]

[ 9 ] Zakaria HY. Article review: Lessepsian migration of zooplankton through Suez Canal and its impact on ecological system. Egyptian Journal of Aquatic Research, 2015, 41(2) : 129-144.

[10] Chen LJ, Liu Q, Peng ZR et al. Rotifer community structure and assessment of water quality in Yangcheng Lake. Chinese Journal of Oceanology and Limnology, 2012, 30(1):47-58.

[11] Chen GR, Zhong P, Zhang XF et al. Zooplankton and its relationship with water quality in Huizhou West Lake. J Lake $S c i, 2008,20$ (3) : 351-356. DOI: 10.18307/2008.0314. [ 陈光荣, 钟萍, 张修峰等. 惠州西湖浮游动物及其与水质 
的关系. 湖泊科学, $2008,20(3): 351-356$. ]

[12] Sommer U, Adrian R, Domis LDS et al. Beyond the plankton ecology group ( PEG) Model: Mechanisms driving plankton succession. Annual Review of Ecology, Evolution, and Systematics, 2012, 43: 429-448.

[13] Wang ZH, Gui HR, Luo ZX et al. The response of plankton in excavating coal subsidence pool to the mining area ecological changes. China Environmental Science, 2005, 25 (1): 42-46. [王振红, 桂和荣, 罗专溪等. 采煤塌陷塘浮游生物 对矿区生态变化的响应. 中国环境科学, 2005, 25(1): 42-46.]

[14] Deng DG, Xing RL, Ma R et al. Seasonal variations on community structure of crustacean zooplankton in a small lake of an excavating coal subsidence region in Huaibei City. J Lake Sci, 2010, 22(4) : 591-597. DOI: 10.18307/2010.0417. [邓道 贵, 邢荣龙, 马睿等. 淮北采煤塌陷区小型湖泊浮游甲壳动物群落结构的季节变化. 湖泊科学, 2010, 22(4): 591-597.]

[15] Deng DG, Jin XW, Ge Q et al. Seasonal variations on community structure of rotifers in small lakes of an excavating coal subsidence region in Huaibei City. J Lake Sci, 2012, 24(1) : 111-116. DOI: 10.18307/2012.0115. [邓道贵, 金显文, 葛茜等. 淮北采煤塌陷区小型湖泊轮虫群落结构的季节变化. 湖泊科学, 2012, 24(1): 111-116.]

[16] Zhang ZS, Huang XF eds. Research methods in limnoplankton. Beijing: Science Press, 1991. [章宗涉, 黄祥飞. 淡水浮 游生物研究方法. 北京: 科学出版社, 1991.]

[17] Wang JJ ed. Freshwater Rotifera Sinica. Beijing: Science Press, 1961. [王家楫. 中国淡水轮虫志. 北京: 科学出版 社, 1961.]

[18] Jiang XZ, Du NS eds. Fauna Sinica • Arthropoda • Crustacea • Freshwater Cladocera. Beijing: Science Press, 1979. [蒋篎治, 堵南山. 中国动物志 ·节肢动物门・甲壳纲・淡水枝角类. 北京: 科学出版社, 1979.]

[19］Shen JR ed. Fauna Sinica • Arthropoda - Crustacea • Freshwater Copepoda. Beijing: Science Press, 1979. [沈嘉瑞. 中国动物志・节肢动物门 ·甲壳纲・淡水桡足类. 北京: 科学出版社, 1979.]

[20] Huang XF ed. Lake ecological survey observation and analysis. Beijing: Standards Press of China, 2000. [黄祥飞. 湖泊 生态调查观测与分析. 北京: 中国标准出版社, 2000.]

[21] Wang MC, Liu XQ, Zhang JH. Evaluate method and classification standard on lake eutrophication. Environmental Monitoring in China, 2002, 18(5): 47-49. [王明翠, 刘雪芹, 张建辉. 湖泊富营养化评价方法及分级标准. 中国环境监 测, 2002, 18(5): 47-49.]

[22] Jin XC, Tu QY eds. Lake eutrophication investigation specification. Beijing: China Environmental Science Press, 1990. [ 金相灿, 屠清瑛. 湖泊富营养化调查规范. 北京: 中国环境科学出版社, 1990.]

[23] Zhou XY. Research on ecological environment of zooplankton in Coal mining subsided water [Dissertation]. Huainan: Anhui University of Science and Technology, 2005. [周晓燕. 采煤塌陷区水域浮游动物生态环境研究 [学位论文]. 淮 南: 安徽理工大学, 2005.]

[24] Huang HK, Zhao JC. Evaluation of the pollution in Lake Dianehi with zooplankton as indieator. Chinese Journal of Environmental Science, 1992,13(3) : 33-36. [黄海鬼, 赵家聪. 利用浮游动物评价滇池的污染状况. 环境科学, 1992,13 (3) : 33-36.]

[25] Yang LJ, Lu GH, Zhu JQ et al. Characteristics of zooplankton community in Hengshan reservoir and water quality assessment. Acta Hydrobiologica Sinica, 2014, 38(4): 720-728. [杨亮杰, 吕光汉, 笈俊全等. 横山水库浮游动物群落结 构特征及水质评价. 水生生物学报, 2014, 38(4): 720-728.]

[26] Li GG, Yu ZM. Community structure of zooplankton in Lake Qiandaohu. Acta Ecologica Sinica, 2002, 22(2) : 156-162. [李共国, 虞左明. 千岛湖浮游动物的群落结构. 生态学报, 2002, 22(2) : 156-162.]

[27] Du X, Feng WS, Li W et al. Response of rotifer community to environmental changes in five shallow lakes in the middle reach of Changjiang River, China. Chinese Journal of Oceanology and Limnology, 2014, 32(5) : 1083-1091.

[28] Morse RE, Friedland KD, Tommasi D et al. Distinct zooplankton regime shift patterns across ecoregions of the US northeast continental shelf large marine ecosystem. Journal of Marine Systems, 2016, 165: 77-91.

[29] Zhao W, Zhao YY, Wang QH et al. The community structure and seasonal dynamics of plankton in Bange Lake, northern Tibet, China. Chinese Journal of Oceanology \& Limnology, 2016, 34(6) : 1143-1157.

[30] Wang L, Wang C, Deng DG et al. Temporal and spatial variations in phytoplankton: Correlations with environmental factors in Shengjin Lake, China. Environmental Science and Pollution Research, 2015, 22: 14144-14156.

[31] Wang C, Wang L, Deng DG et al. Temporal and spatial variations in rotifer correlations with environmental factors in 
Shengjin Lake, China. Environmental Science and Pollution Research, 2016, 23: 8076-8084.

[32] Wang S, Xie P, Wu S et al. Crustacean zooplankton size structure in aquaculture lakes: Is larger size structure always associated with higher grazing pressure? Hydrobiologia, 2007, 575: 203-209.

[33] Egertson CJ, Downing JA. Relationship of fish catch and composition to water quality in a suit of agriculturally eutrophic lakes. Canadian Journal of Fisheries and Aquatic Sciences, 2004, 61: 1784-1796.

[34] Xu M, Wu FY, Liu JJ et al. Seasonal variation of community structure of Crustacean zooplanktons in Lake Jiaoganghu. Chinese Journal of Ecology, 2016, 35(5) : 1254-1262. [徐梅, 吴芳仪, 刘靓郬等. 焦岗湖浮游甲壳动物群落结构的 季节动态. 生态学杂志, 2016, 35(5): 1254-1262.]

[35] Wu DS, Zheng BS, Kang WD et al. Leaching behavior of coal spoils and environment impacts. Earth and Environment, 2004, 32(1) : 55-59. [ 吴代赦, 郑宝山, 康往东等. 煤研石的淋溶行为与环境影响的研究一一以淮南潘谢矿区为 例. 地球与环境, 2004, 32(1): 55-59.]

[36] Pan BZ, Wang HJ, Liang XM et al. Macrozoobenthos in Yangtze oxbows: Community characteristics and causes of resources decline. J Lake Sci, 2008, 20(6) : 806-813. DOI:10.18307/2008.0602. [潘保柱, 王海军, 梁小民等. 长江故 道底栖动物群落特征及资源衰退原因分析. 湖泊科学, 2008, 20(6) : 806-813.]

[37] Zhang OY, Bu HF, Wang CP et al. The influence of water system connectivity of Yangtze River for river health. Yangtze River, 2010, 41(2) : 1-5. [张欧阳, 卜惠峰, 王翠平等. 长江流域水系连通性对河流健康的影响. 人民长江, 2010, 41(2): $1-5$. $]$

[38] Pratiwi NTM, Ardhito, Wulandari DY et al. Horizontal distribution of zooplankton in Tangerang coastal waters, Indonesia. Procedia Environmental Sciences, 2016, 33: 470-477.

[39] Wang D, Lu JJ, Chen PM et al. Community characteristics and of zooplankton in Qinzhou Bay. Acta Ecologica Sinica, 2014, 34: 141-147.

[40] Hou LL. Study on the community charaeteristies of zooplankton of Gaotang Lake in Huainan[Dissertation]. Huainan: Anhui University of Science and Technology, 2007. [侯来利. 淮南市高塘湖水域浮游动物群落特征研究 [学位论文]. 淮 南: 安徽理工大学, 2007.]

[41] Choi JY, Jeong KS, Kim SK et al. Role of macrophytes as microhabitats for zooplankton community in lentic freshwater ecosystems of South Korea. Ecological Informatics, 2014, 24: 177-185.

[42] Schriver P, Bogestrand J, Jeppesen E et al. Impact of submerged macrophytes on fish-zooplankton-phytoplankton interactions: Large-scale enclosure experiments in a shallow eutrophic Lake. Freshwater Biology, 1995, 33: 255-270.

[43] Chen GR, Liu ZW, Zhong P et al. The situation and relation of mycrophyte, zooplankton and fish in the ecological restoration of a tropical shallow lake in a city. Chinese Ecology and Environment, 2007, 16(1): 1-7. [陈光荣, 刘正文, 钟萍 等. 热带城市湖泊生态恢复中水生植被、浮游动物和鱼类的关系研究. 生态环境, 2007, 16(1) : 1-7.]

[44] Hu CY. The density and diversity of zooplanktons in the succession of five lakes. Acta Hydrobiologica Sinica, 1999,23 (3) : 217-226. [胡春英. 不同湖泊演替过程中浮游动物数量及多样性的研究. 水生生物学报, 1999, 23(3): 217-226.]

[45] Yang FJ, Yang Y, Pan H et al. Effect of an enhanced ecological floating bed ( EEFB) on zooplankton community in a polluted river. J Lake Sci, 2011, 23 (4) : 498-504. DOI: 10.18307/2011.0402. [杨凤娟, 杨扬, 潘鸿等. 强化生态浮床原 位修复技术对污染河流浮游动物群落结构的影响. 湖泊科学, 2011, 23(4) : 498-504.] 